\title{
Qualidade de rúcula minimamente processada acondicionada em embalagens de polietileno de alta densidade e nylon poli
}

\author{
Quality of minimally processed rocket packaged in high density polyethylene and poly nylon \\ packaging
}

Calidad de cohete mínimamente procesado envasado en polietileno de alta densidad y poliamida

Recebido: 06/10/2021 | Revisado: 12/10/2021 | Aceito: 14/10/2021 | Publicado: 17/10/2021

\author{
Patrícia Nogueira Matos \\ ORCID: https://orcid.org/0000-0001-6090-8318 \\ Universidade Federal de Sergipe, Brasil \\ E-mail: patynogueriam@hotmail.com \\ Hyrla Grazielle Silva de Araújo Couto \\ ORCID: https://orcid.org/0000-0002-7151-2578 \\ Universidade Federal de Sergipe, Brasil \\ E-mail: hyrlagrazielle@ hotmail.com \\ Genilza Almeida da Graça \\ ORCID: https://orcid.org/0000-0002-9988-4015 \\ Universidade Federal de Sergipe, Brasil \\ E-mail: almeidagenilza@hotmail.com \\ Alysson Caetano Soares \\ ORCID: https://orcid.org/0000-0002-0448-6998 \\ Universidade Federal de Sergipe, Brasil \\ E-mail: alyssoncs1@ hotmail.com \\ Mateus de Carvalho Furtado \\ ORCID: https://orcid.org/0000-0002-1958-9033 \\ Universidade Federal de Sergipe, Brasil \\ E-mail: mateusdecarvalho@hotmail.com \\ Yure Bibiana Soares Menezes \\ ORCID: https://orcid.org/0000-0003-1363-9877 \\ Universidade Federal de Sergipe, Brasil \\ E-mail: ybibiana@hotmail.com \\ Marcelo Augusto Gutierrez Carnelossi \\ ORCID: https://orcid.org/0000-0002-2961-5557 \\ Universidade Federal de Sergipe, Brasil \\ E-mail: carnelossi@ufs.br
}

\begin{abstract}
Resumo
O presente trabalho teve como objetivo avaliar as alterações físico-químicas e bioquímicas de rúcula (Eruca sativa Mill) minimamente processada. O processamento mínimo constituiu-se das etapas de seleção, padronização, lavagem, fatiamento, sanitização, enxágue e centrifugação. Após o processamento as folhas de rúcula minimamente processadas foram acondicionadas em embalagens plásticas de Nylon Poli (NP) e Polietileno de Alta Densidade (PEAD) e armazenadas a $5 \pm 1{ }^{\circ} \mathrm{C}$ por um período de 12 (doze) dias. Durante o armazenamento, a cada três dias foram avaliados os teores de compostos fenólicos, índice de escurecimento (IE), teores de clorofila e carotenoides, teor de sólidos solúveis, acidez total titulável, $\mathrm{pH}$, vitamina $\mathrm{C}$ e atividade da enzima polifenol oxidase. Verificou-se diminuição significativa nos teores de Vitamina $\mathrm{C}$, acidez $\mathrm{e}^{\circ}$ Brix, e aumento no $\mathrm{pH}$ em todos os tratamentos, a partir do $9^{\circ}$ dia de armazenamento. As folhas de rúculas acondicionadas em NP e PEAD também apresentaram aumento nos teores de compostos fenólicos e na atividade da enzima PPO a partir do $9^{\circ}$ dia de armazenamento, o que contribuiu para o aumento no índice de escurecimento. Dessa forma sugere-se que para o processamento mínimo de rúcula podese utilizar embalagens de PEAD e NP por um período de armazenamento de até nove dias.
\end{abstract}

Palavras-chave: Eruca sativa Mill; Minimamente processados; Características físico-químicas e bioquímicas; Embalagem.

\footnotetext{
Abstract

The present work aimed to evaluate the physicochemical and biochemical alterations of minimally processed rocket (Eruca sativa Mill). The minimal processing consisted of the steps of selection, standardization, washing, slicing, sanitizing, rinsing and centrifugation. After processing, the minimally processed rocket leaves were placed in plastic packaging of Nylon Poly (NP) and High Density Polyethylene (HDPE) and stored at $5 \pm 1^{\circ} \mathrm{C}$ for a period of 12
} 
(twelve) days. During storage, phenolic compounds, browning index (IE), chlorophyll and carotenoids, soluble solids, total titratable acidity, $\mathrm{pH}$, vitamin $\mathrm{C}$ and polyphenol oxidase enzyme activity were evaluated. There was a significant decrease in the contents of Vitamin $\mathrm{C}$, acidity and ${ }^{\circ} \mathrm{Brix}$, and increase in $\mathrm{pH}$ in all treatments, from the 9 th day of storage. The arugula leaves conditioned in NP and HDPE also showed an increase in the levels of phenolic compounds and in the activity of the PPO enzyme from the 9th day of storage, which contributed to the increase in the browning index. Thus, it is suggested that for minimum rocket processing, HDPE and NP packages can be used for a storage period of up to nine days.

Keywords: Eruca sativa Mill; Minimally processed; Physicochemical and biochemical characteristics; Packaging.

\section{Resumen}

El presente trabajo tuvo como objetivo evaluar las alteraciones fisicoquímicas y bioquímicas de la rúcula mínimamente procesada (Eruca sativa Mill). El procesamiento mínimo consistió en los pasos de selección, estandarización, lavado, corte, desinfección, enjuague y centrifugación. Después del procesamiento, las hojas de rúcula mínimamente procesadas se colocaron en envases de plástico de Nylon Poly (NP) y Polietileno de Alta Densidad (HDPE) y se almacenaron a $5 \pm 1^{\circ} \mathrm{C}$ por un período de 12 (doce) días. Durante el almacenamiento se evaluaron compuestos fenólicos, índice de pardeamiento (IE), clorofila y carotenoides, sólidos solubles, acidez titulable total, $\mathrm{pH}$, vitamina $\mathrm{C}$ y actividad de la enzima polifenol oxidasa. Hubo una disminución significativa en los contenidos de Vitamina $\mathrm{C}$, acidez y ${ }^{\circ}$ Brix, y un aumento del $\mathrm{pH}$ en todos los tratamientos, a partir del $9^{\circ}$ día de almacenamiento. Las hojas de rúcula acondicionadas en NP y HDPE también mostraron un aumento en los niveles de compuestos fenólicos y en la actividad de la enzima PPO a partir del $9^{\circ}$ día de almacenamiento, lo que contribuyó al aumento del índice de pardeamiento. Por lo tanto, se sugiere que para un procesamiento mínimo de cohetes, los paquetes de HDPE y NP se puedan usar durante un período de almacenamiento de hasta nueve días.

Palabras clave: Eruca sativa Mill; Mínimamente procesado; Características fisicoquímicas y bioquímicas; Envasado.

\section{Introdução}

A Rúcula (Eruca sativa Mill.) é uma hortaliça da família Brassicaceae, originária da Região Mediterrânea, Ásia Ocidental e Norte da África. (Oliveira, 2014). Muito apreciada nas regiões brasileiras de colonização italiana, é rica em potássio, enxofre, ferro e vitaminas A e C. Possui sabor picante, cheiro agradável e acentuado, efeito anti-inflamatório no intestino e desintoxicante para o organismo humano (Trani \& Passos, 1998). Devido a suas características nutricionais o consumo de Rúcula vem aumentando a cada ano e segundo a CEAGESP o consumo de rúcula mais do que quadruplicou nos últimos seis anos (Ceagesp, 2021).

Com o aumento da procura pelos alimentos de pronto uso e com a popularização das hortaliças minimamente processadas no Brasil, os supermercados vêm oferecendo aos consumidores folhas de rúcula cortadas, limpas, higienizadas e embaladas, prontas para consumo. Esses produtos minimamente processados, também conhecidos como "fresh cut", têm-se destacado no mercado, por seguir a tendência mundial de consumo de alimentos saudáveis, frescos e de alta qualidade (Barreto et al., 2021).

Frutas e hortaliças minimamente processadas são vegetais que passaram por alterações físicas, sendo descascados e/ou picados, e/ou torneados, e/ou ralados, dentre outros processos, mas mantidos em estado fresco e metabolicamente ativos (Vilas Boas, 2012). Segundo Junqueira e Luengo (2000), a vantagem dos produtos minimamente processados é a de disponibilizar um produto pronto para se usar, que não requeira nenhuma preparação posterior significativa por parte do consumidor, em termos de seleção, limpeza, lavagem ou cortes, além de reduzir praticamente os desperdícios. No entanto, Alexandra et al., (2019) ressalta que o processamento pode ser entendido como um conjunto de ações que impõem um grande estresse sobre o produto vivo, acelerando a perda da qualidade por anteciparem a senescência.

O processamento mínimo de rúcula é realizado de acordo com as seguintes etapas: pré-resfriamento por três horas em câmaras frigoríficas a $\pm 5^{\circ} \mathrm{C}$ ou por imersão em água, lavagem com água a $5^{\circ} \mathrm{C}$ afim de retirar as sujidades maiores, armazenamento por 12 horas a $10 \pm 2^{\circ} \mathrm{C}$, seleção, padronização, corte, enxágue, sanitização, centrifugação e embalagem (Sigrist, 2002; Gonzalez et al., 2006) 
Segundo Sigrist (2002) temperaturas altas $\left(11^{\circ} \mathrm{C}\right)$ o metabolismo de rúculas minimamente processada ocorre de forma mais acentuada e a temperatura ideal para a rúcula é $5^{\circ} \mathrm{C}$.Danos físicos causados nos tecidos vegetais pelo processamento mínimo da cenoura e o aumento da temperatura influem respectivamente no aumento da taxa de respiração das cenouras e do metabolismo (Spagnol et al, 2006). Souza (2010) por exemplo, verificou que o índice de escurecimento das alfaces americanas minimamente processadas armazenadas nas formas de saladas (acelga, alface americana e alface roxa) em embalagens PEAD aumentou durante o armazenamento. $\mathrm{O}$ uso de embalagens adequadas para o armazenamento de produtos minimamente processadas podem, minimizar a perda de água, reduzir a taxa respiratória durante o armazenamento, bem como facilitar o transporte, manipulação e a venda dos mesmos (Carnelossi, 2002). A qualidade e a segurança dos vegetais minimamente processados estão intimamente relacionados à metodologias de processamento, ao uso de embalagem apropriadas e às condições de armazenamento, e são fatores que podem ser adaptados, sem grandes dificuldades, no processamento desses produtos (Lima, 2011).

Dessa forma o objetivo deste trabalho foi avaliar o comportamento da rúcula minimamente processada, acondicionada em embalagens de polietileno de baixa densidade (PEAD) e nylon poli (NP), buscando a melhor embalagem para o armazenamento.

\section{Materiais e Métodos}

O presente estudo consiste em uma pesquisa laboratorial (Estrela, 2018), onde foi avaliado o comportamento póscolheita de folhas de rúcula submetidas a diferentes tratamentos. Folhas de rúcula (Euruca sativa) foram adquiridas na maturação hortícola e mantidas sob refrigeração $( \pm 5 \circ \mathrm{oC})$ até o momento do processamento.

O processamento mínimo da rúcula foi realizado seguindo a metodologia apresentada por Gonzalez et al. (2006) com adaptações. As folhas de rúcula foram selecionadas e padronizadas pela aparência visual e integridade física, retirando-se folhas amareladas murchas e danificadas, em seguida, lavadas com água corrente para retirada das sujidades. O corte foi realizado manualmente removendo-se os caules das folhas. As folhas cortadas foram então imersas em água resfriada a $5 \pm 1^{\circ} \mathrm{C}$, contendo $150 \mathrm{mgL}-1$ de cloro ativo, por $10 \mathrm{~min}$. O enxágue foi realizado em solução resfriada a $5 \pm 1^{\circ} \mathrm{C}$ de cloro ativo contendo 3mgL-1 durante 10min. As folhas foram centrifugadas por $5 \mathrm{~min}$ em centrífuga (SKYNSEN SDF-20) própria para alimentos. Amostras de $80 \mathrm{~g}$ de rúcula minimamente processada foram então acondicionadas em embalagens de Polietileno de Alta Densidade (PEAD) e Nylon poli (NP) e armazenadas em expositor vertical a $5 \pm 1^{\circ} \mathrm{C}$ por um período de 12 dias. A cada três dias foram realizadas análises de $\mathrm{pH}$, acidez total titulável (ATT), teor de sólidos solúveis, vitamina $\mathrm{C}$, índice de escurecimento, polifenoloxidase (PPO), teor de fenóis e clorofila e carotenóides.

Os teores de sólidos solúveis totais (SST) foram determinados a partir do extrato obtido após a maceração da rúcula. Utilizou-se um refratômetro Abbé (tipo WYA 2WA-J, BIOBRIX) e os resultados foram expressos em ${ }^{\circ}$ Brix.

A acidez titulavél total (ATT) foi determinada de acordo com o descrito pelo IAL (2008), utilizou-se $50 \mathrm{ml}$ da solução utilizada para a determinação do $\mathrm{pH}$, adicionando-se o indicador fenolftaleína a $1 \%$, e titulado com $\mathrm{NaOH}(0,1 \mathrm{~N})$, a ATT foi expressa em g de ácido málico/ 100g de matéria fresca (MF).

$\mathrm{O}$ pH foi determinado em pH-metro digital em $50 \mathrm{~mL}$ de solução obtida pela homogeneização e filtragem de 5,0 g da amostra em água destilada (IAL, 2008).

Os teores de vitamina C foram determinados utilizando metodologia descrita por Carnelossi (2000).

O índice de escurecimento do produto foi acompanhado utilizando-se um colorímetro portátil digital (MINOLTA CR400), a avaliação foi feita diretamente sobre a superfície, pela escala Hunter (CIELAB), tomando-se como base os valores de $\mathrm{L}^{*}$ que indica luminosidade (claro/escuro); $\mathrm{a}^{*}$ que indica cromaticidade no eixo da cor verde (-) para a vermelha (+); e b* indica cromaticidade no eixo da cor azul (-) para amarela (+). Os valores obtidos foram utilizados para calcular o índice de 
escurecimento de acordo com Palou et al. (1999), onde $\mathrm{IE}=[(100(\mathrm{x}-0,31) / 0,172]$ em que $\mathrm{x}=(\mathrm{a}+1,75 \mathrm{~L}) /(5,645 \mathrm{~L}+\mathrm{a}-$ $3,012 b)$.

A determinação da atividade da enzima polifenoloxidase (PPO) foi realizada de acordo com o Simões (2004). O extrato enzimático foi obtido homogeneizando-se $1 \mathrm{~g}$ do material vegetal em $6 \mathrm{~mL}$ de tampão fosfato $(0,2 \mathrm{M}) \mathrm{em} \mathrm{pH} 6,0$. A seguir, o material foi centrifugado a $10.000 \mathrm{~g}$ por 21 minutos a $4^{\circ} \mathrm{C}$. Após a centrifugação, o sobrenadante foi colocado em um tubo em banho gelo. Em outro tubo de ensaio adicionou-se $1,3 \mathrm{~mL}$ de tampão fosfato $(0,2 \mathrm{M}) \mathrm{em} \mathrm{pH} 6,0$ e 1,5 mL de catecol $(0,2 \mathrm{M})$, permanecendo a $25^{\circ} \mathrm{C}$ até a estabilização da temperatura. Após essa etapa, adicionou-se ao tubo de ensaio $30 \mu \mathrm{L}$ do sobrenadante, homogeneizou-se e imediatamente foram realizadas leituras de absorbância a $425 \mathrm{~nm}$ de $30 \mathrm{em} 30 \mathrm{~s}$, até 2 minutos. Uma unidade enzimática de PPO foi definida como a quantidade de enzima no extrato capaz de aumentar a absorbância em 0,001 unidade por minuto. Como branco, foi utilizado a solução com 1,3 mL de tampão fosfato (0,2 M) e 1,5 $\mathrm{mL}$ de catecol $(0,2 \mathrm{M})$ a $25^{\circ} \mathrm{C}$.

Os fenóis totais foram determinados de acordo com a metodologia de Kubota (1995), com adaptações. Amostras (5 g) do material vegetal foram maceradas e homogeneizadas com $30 \mathrm{~mL}$ de água destilada e, em seguida, filtradas em gaze em balão de $50 \mathrm{~mL}$. Para determinação dos teores de fenóis foi construída uma curva padrão de D-catequina em concentração de 0; 25; 50; 75 e $100 \mu \mathrm{g}$. A curva foi preparada utilizando-se $1 \mathrm{~mL}$ de cada concentração em tubos de ensaio e adicionados $9 \mathrm{~mL}$ de água destilada. Foi adicionado em cada tubo $5 \mathrm{~mL}$ de solução diluída de Folin-Ciocalteau ( $1 \mathrm{~mL}$ de reagente de Folin ( $2 \mathrm{~N}$ ) em $9 \mathrm{~mL}$ de água destilada) e misturado em um Vortex, após $30 \mathrm{seg}$. depois da adição do reativo de Folin-Ciocalteau, mas antes de $8 \mathrm{~min}$ foram adicionados $4 \mathrm{~mL}$ de solução de carbonato de sódio $(10 \%)$. Os tubos foram colocados por $1 \mathrm{~h}$ a $30{ }^{\circ} \mathrm{C}$ (banho de água) e logo após transferidos para $0{ }^{\circ} \mathrm{C}$ (banho de gelo) onde ficaram mantidos por aproximadamente $1 \mathrm{~h}$ com a finalidade de paralisar a reação de oxidação. A determinação de fenóis foi realizada pipetando-se $0,5 \mathrm{~mL}$ do extrato preparado em tubo de ensaio teste e adicionados $4,5 \mathrm{~mL}$ de água destilada. Posteriormente foram adicionados $5 \mathrm{~mL}$ de reagente de Folin diluído e misturou-se no Vortex. Em seguida, foram utilizados os procedimentos para o preparo da curva padrão como descrito acima. A concentração foi calculada diretamente utilizando a curva padrão.

O teor de clorofila e carotenóides total foram determinados, seguindo o método proposto por Lichtenthaler (1987), com algumas adaptações. A extração foi realizada por meio da homogeneização de $2 \mathrm{~g}$ de amostra com $0,2 \mathrm{~g}$ de carbonato de cálcio e $7 \mathrm{~mL}$ de acetona $80 \%$ em um almofariz. O extrato foi filtrado em balão volumétrico e completado com acetona $80 \%$ para $25 \mathrm{~mL}$. A absorbância foi determinada em espectrofotômetro a 470, 647 e $663 \mathrm{~nm}$. Os valores obtidos foram utilizados para calcular o teor de clorofila e carotenóides total do produto, onde utilizou-se a seguinte equação: Clorofila $(T)=7,15 \cdot A 663,2+$ 18,71 A646,8 e Carotenóides $=[1000 \cdot$ A470 $-(1,82 \cdot \mathrm{Ca}-104,96 \cdot \mathrm{Cb})] / 198$, onde Clorofila a $(\mathrm{Ca})=12,25 \cdot$ A663,2 $-2,79$ - A646,8 e ; Clorofila b (Cb) = 25,50 · A 646,8 - 5,10 • A663,2.

$\mathrm{O}$ experimento foi conduzido em delineamento experimental inteiramente casualizado em esquema fatorial $2 \times 5$, sendo duas embalagens (PEAD e NP), e cinco períodos de armazenamento (0, 3, 6, 9 e 12), totalizando 10 tratamentos com quatro repetições por tratamento. As análises estatísticas foram realizadas com o auxílio do programa ASSISTAT. Após a análise de variância, as médias, foram comparadas pelo teste de Tukey a 5\% de probabilidade $(\mathrm{P}<0,05 \%)$.

\section{Resultados e Discussão}

Foi verificada redução nos teores de acidez titulável nas folhas de rúcula nos dois tratamentos utilizados (Figura1A). 
Figura 1: Acidez Titulável Total (A), pH (B), Teores de vitamina C (C) e Sólidos Solúveis (D) de folhas de rúcula minimamente processada acondicionada em embalagens de Nylon Poli (NP) e Polietileno de Alta Densidade (PEAD) e armazenadas a $5 \pm 1^{\circ} \mathrm{C}$.

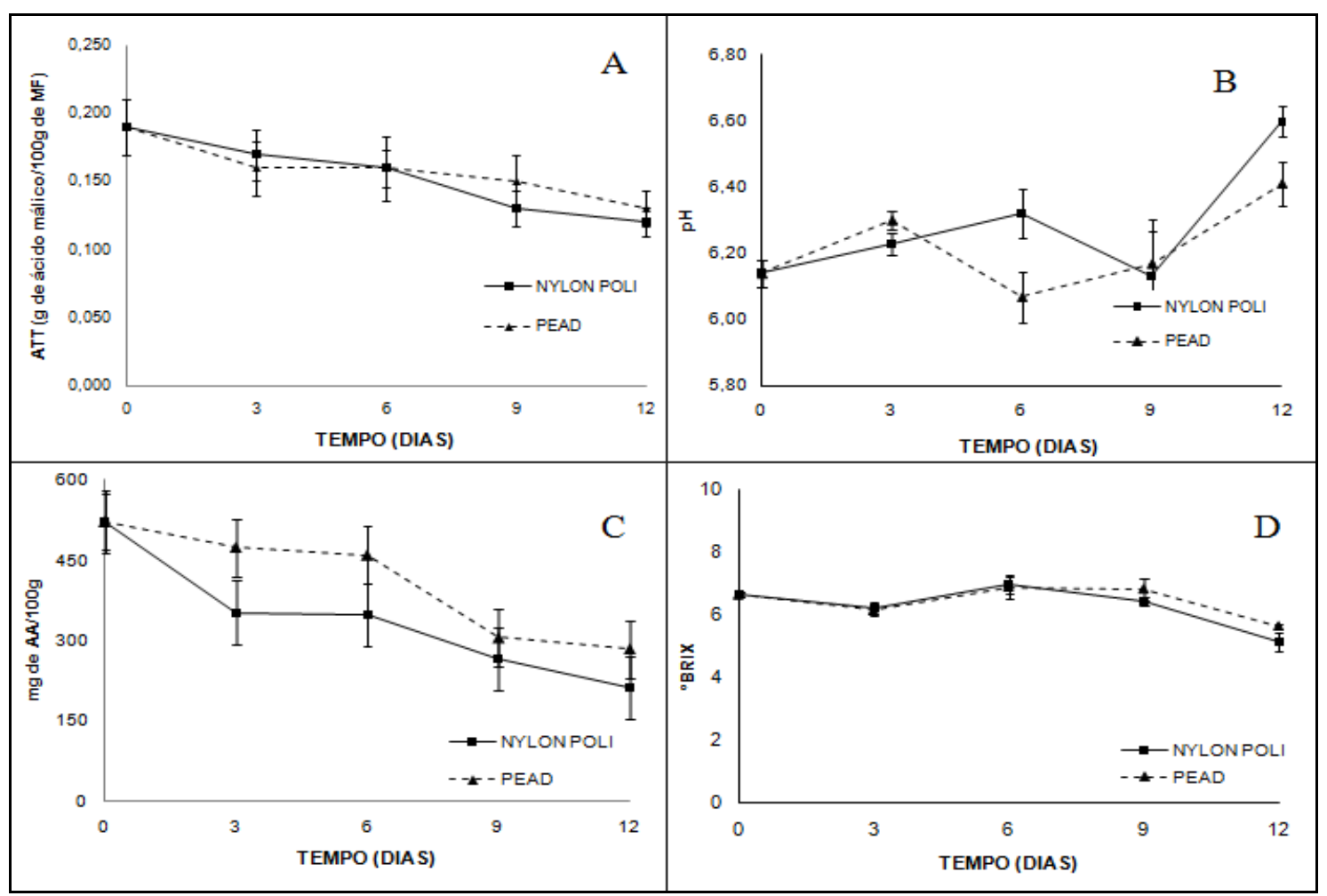

Fonte: Autores.

De acordo com Francisco et al. (2020) a diminuição da acidez titulável durante o armazenamento é resultado da degradação da pectina e a consequente produção de ácidos orgânicos durante a glicólise, seguida pela hidrólise dos ácidos durante o processo de respiração celular aeróbica. Roura et al. (2000), a diminuição da acidez durante o armazenamento pode estar relacionada ainda com uma respiração maior do tecido vegetal logo após o processamento mínimo, devido ao consumo dos ácidos orgânicos (substâncias de reserva) no processo respiratório, ou ainda de sua conversão em açúcares (Souza, 2010). Rúcula minimamente processada apresentaram ao longo do período de armazenamento, aumento de $\mathrm{pH}$ nos dois tratamentos analisados (Figura 1-B), porém não houve variação do pH entre as amostras dos dois tratamentos até o nono dia de avaliação, a partir do qual verificou-se um aumento nos niveis de $\mathrm{pH}$ em todos os produtos. Resultados semelhantes foram encontrados em estudos realizados por Moreno et al. (2016) onde foi observado que o $\mathrm{pH}$ do repolho minimamente processado na temperatura de $8^{\circ} \mathrm{C}$ aumentou até o oitavo dia de armazenamento. Silva (2001) não encontrou efeito significativo no pH em repolhos minimamente processados, embalados em filmes de polietileno, de baixa e alta densidade, e polipropileno, armazenados por 15 dias na temperatura de $5^{\circ} \mathrm{C}$. Segundo este autor, o $\mathrm{pH}$ variou muito pouco com o tempo, apresentando um pequeno aumento, nas três embalagens estudadas.

$\mathrm{O}$ aumento do $\mathrm{pH}$ pode ser associado ao inicio do processo de senescência, pois durante esse período os processos catabólicos são superiores aos processos anabólicos, é durante a senescência que os frutos ficam mais susceptíveis ao ataque de microrganismos, contribuindo desta forma para o aumento dessa variável. (Marth, 1998). Contudo, este comportamento pode ser explicado também pela resposta do tecido ao neutralizar a acidez gerada pelo CO2 (Kader, 1986).

Os teores de Vitamina $\mathrm{C}$ da rúcula minimamente processada diminuíram ao longo do período de armazenamento (Figura 1-C), no entanto não foi verificada diferença significativa $(\mathrm{p}<0,05 \%)$ neste parâmetro entre as folhas de rúcula 
armazenadas em embalagem de Nylon Poli e PEAD. Indicando que os teores de vitamina $\mathrm{C}$ foram influenciados apenas pelo tempo de armazenamento. Essa diminuição se deve segundo Lee e Kader (2000) a alta sensibilidade à degradação durante a fase de pós-colheita da vitamina C. As perdas de vitamina C podem estar relacionadas os danos mecânicos causados pelo corte nos tecidos com o processamento mínimo, pois os mesmos promovem a desorganização celular ocasionando a oxidação do ácido ascórbico (Alves et al, 2010). Além disso, a vitamina C é sensível aos agentes físico-químicos como luz, oxigênio e calor (Sátiro et al., 2020). Os resultados obtidos no presente trabalho corroboram com os de Sigrist (2002) o qual também verificou redução no teor de vitamina $\mathrm{C}$ em rúculas minimamente processadas ao longo do armazenamento, o que o autor atribui as altas concentrações de $\mathrm{O} 2$ utilizadas no interior de embalagens de PVC.

Os teores de sólidos solúveis das folhas de rúcula minimamente processadas mantiveram-se praticamente constantes nos dois tratamentos durante todo período de armazenamento, não apresentando diferença significativa ( $\mathrm{P}, 0,05 \%)$ entre si. No entanto, após o nono dia verificou-se diminuição nos teores de sólidos solúveis nas folhas de rúcula dos dois tratamentos (Figura 1D). Segundo Silva (2001), este comportamento pode ter ocorrido provavelmente, devido ao baixo metabolismo do produto na temperatura de $5^{\circ} \mathrm{C}$, associado com as altas concentrações de $\mathrm{CO} 2$ no interior das embalagens, reduzindo os processos metabólicos e, consequentemente, o consumo das reservas celulares. Reinoso (2011) verificou em repolhos que o processamento não causou grandes perdas nos teores de sólidos solúveis, ele concluiu, portanto que tal fato pode ter ocorrido devido estabilização da atmosfera no interior da embalagem pelo filme (nylon poli) utilizado, reduzindo dessa forma o consumo das reservas celulares.

Rúculas acondicionadas em embalagens NP e PEAD apresentaram variações nos índices de escurecimento (IE) durante o armazenamento, no entanto, a partir do nono dia de armazenamento verificou-se aumento no IE das folhas (Figura 2A).

Figura 2: Intensidade de Escurecimento (A), Atividade da Polifenoloxidase (B) e Fenóis Solúveis Totais (C) para folhas de rúcula minimamente processada acondicionada em embalagens de Nylon Poli (NP) e Polietileno de Alta Densidade (PEAD) armazenadas a $5^{\circ} \mathrm{C}$.

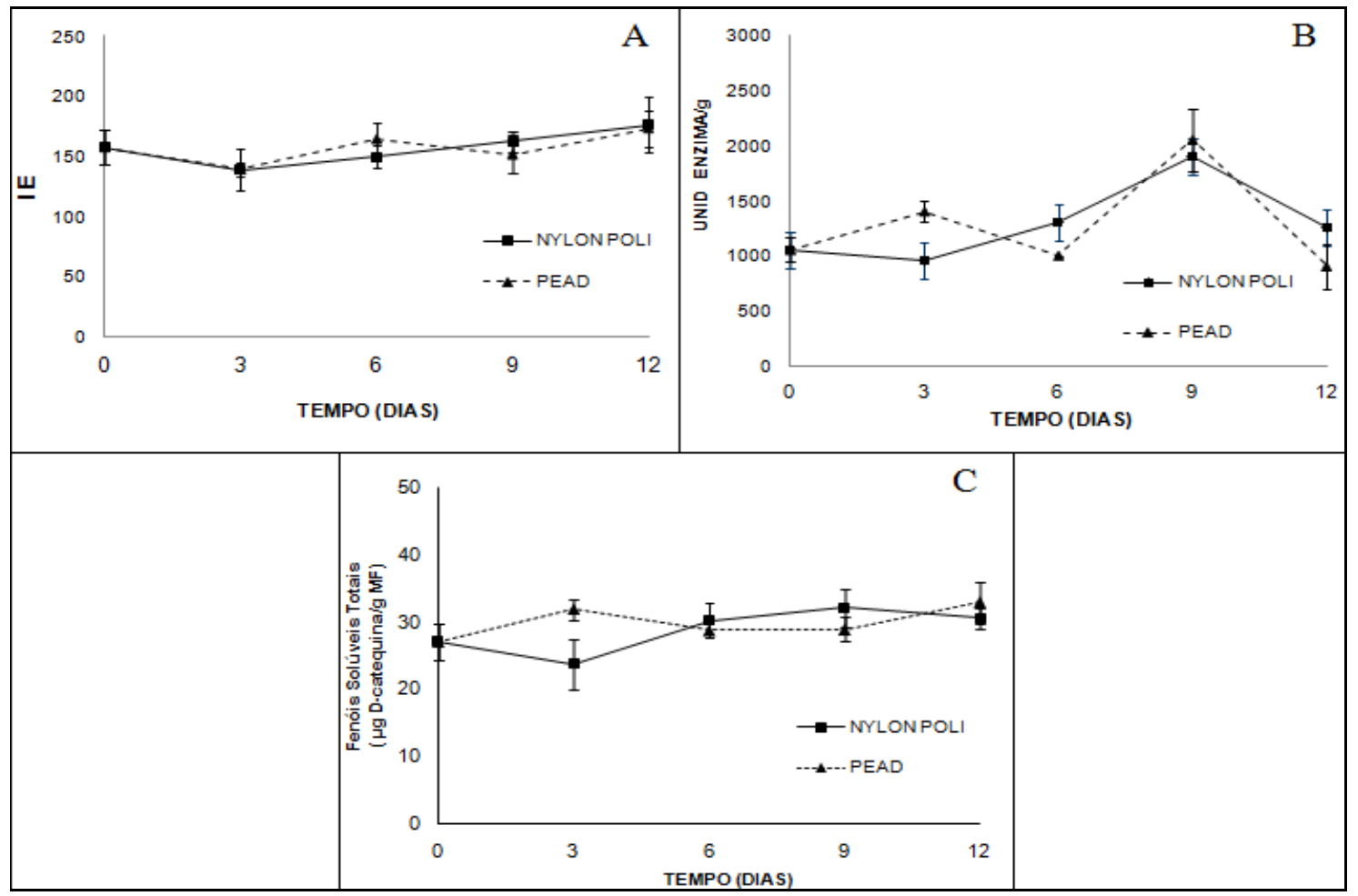

Fonte: Autores. 
Dados esses que corroboram com Reinoso (2011), que trabalhando a acelga sob atmosfera modificada ativa e passiva armazenada como parte da salada verificou aumento no IE durante o período de armazenamento.

$\mathrm{O}$ aumento do indice de escurecimento da rúcula pode ter sido ocasionado pelos danos mecânicos causados pelo processamento, pois os estresses mecânicos são responsáveis pelas mudanças na cor dos produtos minimamente processados (Rocha et al., 2003).

A atividade da polifenoloxidase (PPO) das folhas de rúcula permaneceu constante até aproximadamente o sexto dia, verificou-se também que não houve diferença significativa entre a atividade da PPO das folhas acondicionadas nas embalagens utilizadas (Figura 2B). O aumento da PPO da rúcula acentuou-se a partir do nono dia de armazenamento o que ocasionou o escurecimento das folhas (Figura 2A), esses efeitos são consequência do estresse mecânico ocasionado no processamento mínimo e aumento dos processos catábolicos influenciado pelo período de senescência. Rinaldi et al (2009) trabalhando com repolho minimamente processado verificou aumento significativo no teor da PPO, e maior incremento no escurecimento, dados que corroboram com o presente estudo.

Moretti et al. (2002) citam que os danos mecânicos (corte) causados durante o processamento podem aumentar a concentração de dióxido de carbono, etileno e de água livre, causar alterações no sabor e aroma. Simões et al., (2019) afirma que estes danos promovem a liberação de enzimas que em contato com os seus substratos contribuem para o escurecimento enzimático

Os teores de fenóis totais das folhas de rúcula permaneceram constantes durante o tempo de armazenamento, avaliando-se os tratamentos utilizados verificou-se que não houve diferença entre produtos acondicionados nas embalagens de NP e PEAD (Figura 2C). Em concordância com o presente estudo, no qual não se verificou variação nos teores de compostos fenólicos, Souza (2010), evidenciou que alface roxa acondicionada em forma de salada mista com atmosfera ativa, manteve os teores de fenóis sem variações durante os 15 dias de armazenamento.

$\mathrm{O}$ aumento dos compostos fenólicos no produto pode ocorrer quando há uma menor atividade das enzimas PPO e POD, e portanto menor consumo de substrato (Medeiros, 2009).

Os teores de clorofila e carotenóides das folhas de rúcula apresentaram diferença significativa $(\mathrm{P}<0,05 \%)$ durante o período de armazenamento, no entanto os teores de clorofila e carotenóides não variaram quando nas embalagens utilizadas (Figura 3).

Figura 3: Clorofila (A) e Carotenóides (B) para folhas de rúcula minimamente processada acondicionada em embalagens de Nylon Poli (NP) e Polietileno de Alta Densidade (PEAD) armazenadas a $5^{\circ} \mathrm{C}$.

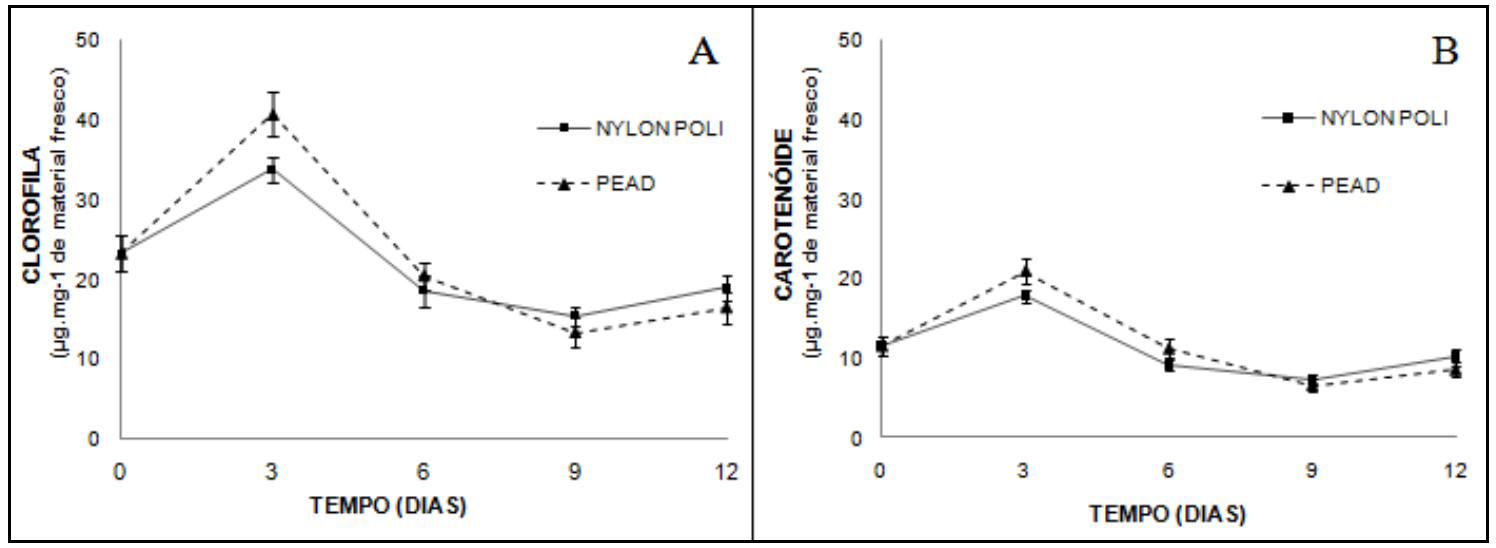

Fonte: Autores.

Carnelossi (2000) relata que couves em embalagens de baixa permeabilidade a 1 a $5^{\circ} \mathrm{C}$ mantiveram os teores de clorofila e carotenoides constantes durante 15 dias, havendo degradação da clorofila no $10^{\circ}$ dia nas couves acondicionas a 
$10^{\circ} \mathrm{C}$. O processo de senescência dos tecidos vegetais ocasiona a degradação da clorofila, principal pigmentos das hortaliças, porém o processamento mínimo torna-o ainda mais susceptível à degradação por induzir os tecidos vegetais a mudanças estruturais e químicas (Sigrist, 2002). A degradação de carotenoides em vegetais minimamente processados pode-se dar como resposta ao estresse do corte, estimulando enzimas envolvidas na cicatrização e reparação de membranas (Rolle \& Chism, 1987).

\section{Conclusão}

As folhas de rúcula minimamente processada acondicionadas em embalagens Nylon poli (NP) e Polietileno de Alta Densidade (PEAD) apresentaram parâmetros bioquímicos e físico-químicos semelhantes, garantindo condições para a conservação das folhas, uma vez que as rúculas só apresentaram alterações significativas após o nono dia concidindo com o inicio dos processos catabólicos provocados pela senescência das folhas.

Com base nos resultados obtidos sugere-se que para o acondicionamento de rúcula minimamente processada pode-se utilizar embalagens de NP ou PEAD e o armazenamento deve ser realizado por um período de 9 (nove) dias. Para trabalhos futuros com rúcula, sugere-se realizar testes com outros tipos de embalagens e análise sensorial para verificar a aceitabilidade do produto.

\section{Referências}

Alexandra, S. M. L. A., Denise, R. M., Díaz, F. L. S. \& Rodríguez, L. L. (2019). Effects of under-water cutting treatments on oleocellosis development, quality and shelf-life of minimally processed Persian lime fruit. Postharvest Biology and Technology. 156, p. 110.

Alves, J. A., Vilas Boas, E. V. B., Vilas Boas, B. M. \& Souza, E. C. (2010). Qualidade de produto minimamente processado à base de abóbora, cenoura, chuchu e mandioquinha-salsa. Ciênc. Tecnol. Aliment., Campinas, 30(3): 625-34.

Barreto, C. F., Navroski, R., Marques, L. O. D., Santos, R. F., Malgarim, M. B. \& Martins, C. R. (2021). Influência da radiação ultravioleta e aditivos na conservação de kiwis minimamente processados. Brazilian Journal of Food Technology. 24, 1-11. https://doi.org/10.1590/1981-6723.02420

Carnelossi, M. A. G. (2000) Fisiologia pós-colheita de folhas de couve (oleracea cv. Acephala) minimamente processadas. Tese (Doutorado) - Universidade federal de Viçosa-MG.

Carnelossi, M. A. G., Silva, E. O., Campos, R. S., Soares, N. F. F., Minin, V. P. R. \& Puschamann, R. (2002). Conservação de folhas de couve minimamente processadas. Revista Brasileira de Produtos Agroindustriais, Campina Grande. 4(2), 149-55. http://www.deag.ufcg.edu.br/rbpa/rev42/Art427.pdf

CEAGESP - Companhia De Entrepostos E Armazéns Gerais De São Paulo. (2021). Frutas e Hortaliças: Fonte de Prazer e Saúde. 89 p.

Dantas, M. I. S., Minim, V. P. R., Puschmann, R., Carneiro, J. D. S. \& Barbosa, R. I. (2004). Mapa de preferência de couve minimamente processada. Horticultura Brasileira, Brasília, 22(1): 101-103.

Estrela, C. (2018). Metodologia Científica: Ciência, Ensino, Pesquisa. Editora Artes Médicas.

Gonzalez, A. F., Ayub, R. A. \& Reghin, M. Y. (2006). Conservação de rúcula minimamente processada produzida em campo aberto e cultivo protegido com agrotêxtil. Horticultura Brasileira [online], 24(3).

Francisco, C. B., Pellá, M. G., Silva, A. O., Raimundo, K. F., Caetano, J., Linde, G. A., Colauto, N. B. \& Dragunski, D. C. (2020). Shelf-life of guavas coated with biodegradable starch and cellulose-based films. International Journal of Biological Macromolecules, 152, $272-279$.

IAL (2008). Métodos físico-químicos para análise de alimentos/coordenadores Odair Zenebon, Neus Sadocco Pascuet e Paulo Tiglea - São Paulo: Instituto Adolfo Lutz.

Junqueira, A. H. \& Luengo, R. F. A. (2000). Mercados diferenciados de hortaliças. Horticultura Brasileira, Brasília, 18(2): 95-99.

Kader, A. A. (1986). Biochemical and physiological basis for effects of controlled and modified atmospheres on fruits and vegetables. Food Technology, 40, 99-104.

Kubota, N. (1995). Phenolic content and L-phenylalanine ammonialyase activity in peach fruit. In: Linskens, H. F. \& Jackson, J. F (eds.) Modern methods of plant analysis - fruits analysis. New York: Spriger-Verlag. p. 81-94.

Lee, S. K. \& Kader, A. A. (2000). Preharvest and postharvest factors influencing vitamin C content of horticultural crops. Postharvest Biology and technology, 20(3): 207-220

Lichyenyhaler, H. K. (1987). Chlorophylls and carotenoids: pigments of photosynthetic biomembranes. In: Packer, L. \& Douce, R. (Eds). Methods in enzimology. London: Academic Press. p. 350-381. 
Lima, L. C. O. (2011). Compatibilidade de permeabilidade de filmes, plásticos, temperatura e respiração de hortaliças minimamente processadas. In: Encontro Nacional Sobre Processamento Mínimo de Frutas e Hortaliças. Nova Friburgo-RJ: Embrapa Agroindústria de Alimentos, 56p.

Marth, E. H. (1998). Extended shelf life refrigerated foods: microbiological quality and safety. Food Technology, 52:57- 62.

Medeiros, E. A. A. (2009). Deterioração pós-colheita de mandioca minimamente processada. Tese de doutorado, universidade Federal de Viçosa.

Moreno, L. B., Scherwinski, R., Silva, J. M. T., Scalon, S. P. Q. \& Carnevalli, T. O. (2016). Conservação de repolho minimamente processado sob efeito de diferentes embalagens, tempo de estocagem e temperatura. Revista de Agricultura Neotropical, Cassilândia-MS, 3(2): 68-74.

Moretti, C. L., Araújo, A. L., Marouelli, W. A. \& Silva, W. L. C. (2002). Respiratory activity and browning of minimally processed sweet potatoes. Horticultura Brasileira, Brasília, 20(03): 497-500.

Oliveira, S. G. (2014). Alelopatia e potencialidade do consórcio entre rúcula e capim-cidreira. 2014. 74f. Dissertação (Mestrado em Agronomia-Horticultura) - Faculdade de Ciências Agronômicas, Botucatu-SP.

Palou, E., Lópes-Malo, A., Barbosa-Cánovas, G.V., Welti-Chaves, J. \& Swanson, B. G. (1999). polyphenoloxidase activity and color of blanched and high hydrostatic pressure treated banana puree. J. Food Sci. 64(1): 42-5.

Reinoso, A. C. L. (2011). Efeito da atmosfera modificada ativa sobre a conservação de salada mista contendo alface americana (Lactuca sativa var "tainá”), acelga (Beta vulgaris L. var cicla L.), e alface roxa (Lactuca sativa var pira roxa) minimamente processada. Tese (Mestrado em Ciência e Tecnologia de Alimentos) - Universidade Federal de Sergipe, Aracaju.

Rinaldi, M. M., Benedetti, B. C., Sarantópoulos, C. I. G. L. \& Moretti, C. L. (2009). Estabilidade de repolho minimamente processado sob diferentes sistemas de embalagem. Ciência e Tecnologia de Alimentos, Campinas, 29(2): 310-315.

Rocha, A. M. C. N., Coulon, E. C. \& Morais, A. M. M. B. (2003). Effects of vacuum packaging on the physical quality of minimally processed potatoes. Food Service Technology, 3: 81-88.

Rolle, R. \& Chism, G. W. (1987). Physiological consequences of minimally processed fruits and vegetables. Journal of Food Quality. Oxford,10: 157-177.

Roura, S. I., Davidovich, L. A. \& Del Valle, C. E. (2000). Quality loss in minimally processed swiss related to amount of damage area. Lebensmittel Wissenschaft und Technology 23: 53-59.

Santos, J. S. \& Oliveira, M. B. P. P. (2012). Review: Fresh, minimally processed foods packaged under modified atmosphere. Brazilian Journal of Food Technology., Campinas, 15(1): 1-14.

Sátiro, L. de S., Costa, F. B. da., Nascimento, A. M. do., Silva, J. L. da., Nobre, M. A. F., Araújo, C. R. de., Gadelha, T. M. \& Lira, R. P. de. (2020). Avaliação da qualidade físico-química da abóbora brasileira minimamente processada (Cucurbita moschata). Pesquisa, Sociedade e Desenvolvimento, 9(5), e58953202.

Sigrist, J. M. M. (2002). Estudos fisiológicos e tecnológicos de couve-flor e rúcula minimamente processadas, 112p, Tese (doutorado) Escola Superior de Agricultura Luiz de Queiroz, Piracicaba.

Silva, E. O. (2001). Fisiologia pós colheita de repolho (Brassica oleracea cv. Capitata) minimamente processado. Viçosa, MG, 90p. Tese (Doutorado em Fisiologia Vegetal) Departamento de Biologia, Universidade Federal de Viçosa (UFV).

Simões, A. N. (2004). Alterações químicas e atividades de enzimas em folhas de couve inteiras e minimamente processadas, 75 F. Dissertação (Mestrado em Fisiologia Vegetal) - Universidade Federal de Viçosa, Viçosa-UFV.

Simões, A. N., Coelho, D. G., Fonseca, K. S., Júnior, A. P. B., Ferreira-Silva, S. L., Freire, C. S. \& Silva, E. F. (2019). Effect of multilayer nylon packages on the oxidative damage of minimally processed yam. Brazilian Journal of Food Technology [online], 22. DOI. https://doi.org/10.1590/1981-6723.09017

Souza, J. F. (2010). Alterações bioquímica e fisiológicas de salada mista minimamente processada composta por alface americana, alface roxa e acelga. Tese (Mestrado em Ciência e Tecnologia de Alimentos) - Universidade Federal de Sergipe, Aracaju.

Spagnol, W. A., Park, K. J. \& Sigrist, J. M. M. (2006). Taxa de respiração de cenouras minimamente processadas e armazenadas em diferentes temperaturas. Ciênc. Tecnol. Aliment. 26(3): 550-554. http://dx.doi.org/10.1590/S0101-20612006000300011.

Trani, P. E. \& Passos, F. A. (1998). Rúcula (Pinchão). In; Fahl, J.I; Camargo, M. B. P. de; Pizinatto, M. A.; Betti, J. A.; Melo, A.M.T. de; Demaria, I. C. \& Furlani, A. M. C. (Eds.) Instruções agrícolas para as principais culturas econômicas. IAC, P 241-242. (IAC. Boletim, 200).

Vilas Boas, B. M., Siqueira, H. H., Leme, S. C., Lima, L. C. O. \& Alves, T. C. (2012). Conservação de pimentão verde minimamente processado acondicionado em diferentes embalagens plásticas. Pesqui. Agropecu. Trop. 42(1): 34-39. http://dx.doi.org/10.1590/S1983-40632012000100005. 